(2) Open Access Full Text Article

\title{
Prevention of organ rejection in renal and liver transplantation with extended release tacrolimus
}

This article was published in the following Dove Press journal:

Transplant Research and Risk Management

2 September 2014

Number of times this article has been viewed

\section{Michael E Reschen Christopher A O'Callaghan}

Henry Wellcome Building, Nuffield Department of Medicine, University of Oxford, Oxford, United Kingdom

Correspondence: Christopher A O'Callaghan

Henry Wellcome Building, University of Oxford, Roosevelt Drive, Oxford, OX3 7BN, United Kingdom

Email chris.ocallaghan@ndm.ox.ac.uk
Abstract: Tacrolimus is the key immunosuppressant used to prevent allograft rejection in kidney and liver transplant recipients. Despite the efficacy of tacrolimus and adjunctive immunosuppressants, a substantial number of patients experience episodes of acute rejection and late graft loss. Nonadherence is an etiological factor in both acute rejection and graft loss. In 2007, a prolonged release version of tacrolimus became available that allows once daily administration, thus halving the pill burden compared to the standard twice-daily tacrolimus. An increasing number of studies in de novo transplantation and in treatment conversion have evaluated the pharmacokinetic profile, efficacy, and safety of prolonged-release tacrolimus. We have reviewed the literature on the use of prolonged-release tacrolimus and hope that this will be of value in the design of protocols for transplant immunosuppression.

Keywords: immunosuppression, kidney, hepatic, allograft, adherence

\section{Introduction}

Transplantation of allogeneic organs into immunocompetent hosts typically leads to immune-mediated destruction of the organ. The development of immunosuppressive drugs that effectively prevent organ rejection has led to transplantation being the preferred treatment for end-stage renal failure and the only treatment for liver failure. In contemporary clinical practice, cell-mediated immunity driven by activated $\mathrm{T}$ cells is the predominant mode of rejection, though antibody-mediated rejection may also occur, most typically in the acute phase. Calcineurin inhibitors (CNI) have become the cornerstone of immunosuppressive regimens for both kidney and liver transplantation.

The two CNIs in common use are cyclosporine and tacrolimus. Tacrolimus forms a complex with FK506 binding protein (FKBP12), which inhibits the enzymatic phosphatase activity of calcineurin. This abrogates the calcineurin-dependent activation of nuclear factor of activated $T$ cells transcription factor, causing a reduction in interleukin 2 production and, consequently, in T cell activation and proliferation. The robust efficacy of CNI-based regimens has been associated with a reduction in the cumulative incidence of a first episode of acute rejection to less than $20 \%$ at 60 months post-transplantation, and a 5-year graft survival of $73 \%$ and $84 \%$ for deceased donor and living kidney donor recipients, respectively, in the US. ${ }^{1}$ A number of studies have shown that tacrolimus can be somewhat more effective than cyclosporine in preventing acute rejection and allograft failure..$^{2-5}$

Since tacrolimus was licensed for liver and kidney transplantation in the 1990s, it has become progressively more popular, such that, by 2010, it was a component of about $90 \%$ of immunosuppression regimens for kidney or liver transplant recipients 
in the US. ${ }^{1,6}$ Nevertheless, as with cyclosporine, tacrolimus has a narrow therapeutic index and requires trough druglevel monitoring to confirm therapeutic levels and avoid toxic levels. Excessive immunosuppression increases the risk of infectious, metabolic, and malignant complications, whilst subtherapeutic levels allow acute rejection and organ failure. In the case of calcineurin inhibitors, high levels are also associated with significant nephrotoxicity.

Tacrolimus was initially developed as an immediate release preparation that is taken twice daily to maintain consistent therapeutic levels (herein referred to as TAC BID). In 2007, Astellas Pharma Inc. (Tokyo, Japan) marketed a prolonged release version (herein referred to as TAC QD) in Europe with the aim of reducing pill burden and improving adherence. The tacrolimus component itself remains unchanged but is encased in a capsule that delays tacrolimus release and absorption. Suboptimal adherence is thought to be a major contributing factor to allograft failure, particularly in kidney transplant recipients for whom a viable alternative exists in the form of dialysis. ${ }^{7-9}$ In general, adherence is better with once daily compared to twice daily medications. ${ }^{10}$ Furthermore, the evening dose is more often omitted than the morning dose. In addition to improving compliance, the altered pharmacokinetic profile of TAC QD could have a beneficial influence on side effects.

Since the development of TAC QD, many studies have evaluated its pharmacokinetic profile, efficacy, safety, and effect on adherence. In this article, we review the data comparing the use of TAC QD to TAC BID in both the stable conversion and de novo transplantation settings.

\section{Methods}

We performed a literature search of the PubMed and Web of Science databases in April 2014 using search terms comprising: "extended release tacrolimus or prolonged release tacrolimus" and "kidney or liver". We manually reviewed the studies and considered only those that had more than five participants, were written in English, and for which the full text manuscript was available. In addition, further studies were manually curated from the reference lists of each manuscript.

\section{De novo renal transplantation}

TAC QD has been evaluated against TAC BID in six randomized controlled trials for the prevention of rejection in de novo kidney transplant recipients (Table 1). ${ }^{1-16}$ In 2013, a systematic review that included five of these studies concluded that there were no differences in biopsy-proven acute rejection or patient survival. ${ }^{17}$ The review included one randomized controlled trial in abstract form that used an alternative preparation of modified release tacrolimus, tacrolimus-LCP (LifeCycle Pharma, now Veloxis Pharmaceuticals, Hørsholm, Denmark), that has different pharmacokinetic parameters to the more commonly used TAC QD preparation, which is the Astellas Pharma Inc. product Advagraf/Astragraf XL. ${ }^{18}$ The largest randomized controlled trial, the open-label Optimising immunoSuppression After Kidney transplantation with ADVAGRAF (OSAKA) trial, randomized 1,251 patients to four different treatment arms comprising TAC BID $0.2 \mathrm{mg} / \mathrm{kg}$, TAC QD $0.2 \mathrm{mg} / \mathrm{kg}$, TAC QD $0.3 \mathrm{mg} / \mathrm{kg}$, and TAC QD $0.2 \mathrm{mg} / \mathrm{kg}$ plus basiliximab plus steroid avoidance. ${ }^{11}$ All patients received mycophenolate and steroids except for the basiliximab group. Trough tacrolimus levels were initially higher in the arm taking $0.3 \mathrm{mg} / \mathrm{kg}$ TAC QD, but were similar from day 14 onwards and, at week 24, the median tacrolimus concentrations were between 7.7 and $8.3 \mathrm{ng} / \mathrm{mL}$ across all four arms. ${ }^{11}$ In all arms, the dose tended to decrease over the duration of the study and was slightly higher overall in the TAC QD groups. The investigators assessed TAC QD efficacy for noninferiority based on a composite primary endpoint of graft loss, biopsy-confirmed acute rejection, or an modified diet in renal disease (MDRD) estimated glomerular filtration rate $(\mathrm{eGFR})<40 \mathrm{~mL} / \mathrm{min} / 1.73 \mathrm{~m}^{2}$. Noninferiority was only demonstrated for TAC QD $0.2 \mathrm{mg} / \mathrm{kg}$ compared to TAC BID $0.2 \mathrm{mg} / \mathrm{kg}$ (primary endpoint reached in $42.2 \%$ versus $40.6 \%$, respectively), but was not demonstrated in the steroid avoidance TAC QD group (treated with additional basiliximab) or in the higher dose TAC QD group. ${ }^{11}$ The seemingly high failure rate of the primary outcome was influenced by the high number of extended criteria donor organs (50\%) contributing to an eGFR below the threshold of $40 \mathrm{~mL} / \mathrm{min} / 1.73 \mathrm{~m}^{2} .{ }^{11}$ Similar numbers of patients experienced biopsy-proven acute rejections across the four arms (10.3\%-16.1\%). TAC QD was also found to be noninferior when compared to a cyclosporine-based immunosuppression regimen with follow-up to 12 months. ${ }^{16}$ The other four randomized trials also found no significant difference in graft survival or biopsy-proven acute rejection to a maximum of 12 months follow-up. ${ }^{12-15}$ Overall, the results of these randomized trials suggest that the efficacy of TAC QD is similar to that of TAC BID using a similar initial starting dose.

Investigators have sought more subtle indications of benefit arising from the altered pharmacokinetic profile of a once-daily drug. The rate of toxic tubulopathy in protocol biopsies did not differ between TAC QD and TAC BID. ${ }^{12}$ However, concomitant pharmacokinetic analysis 


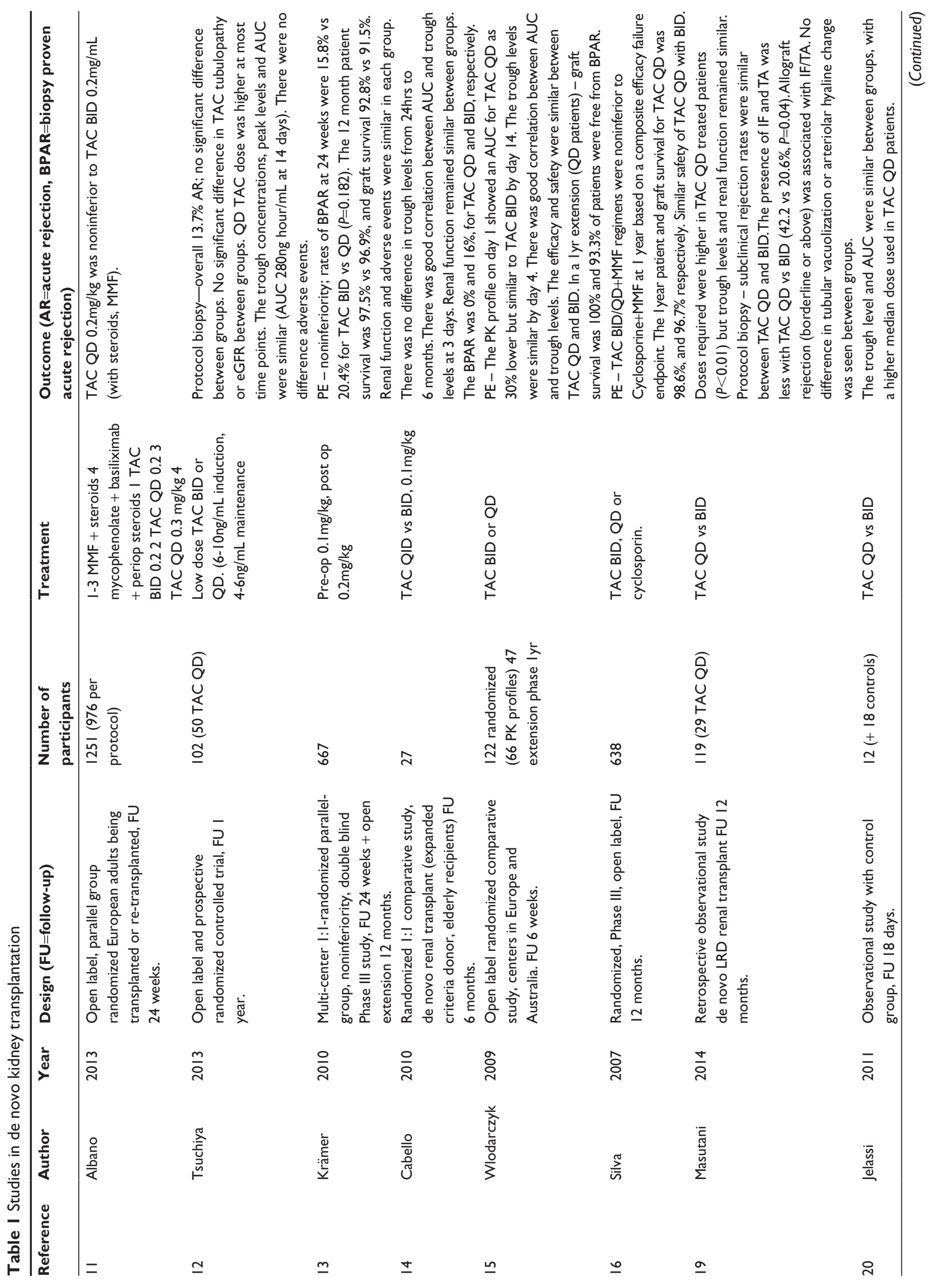




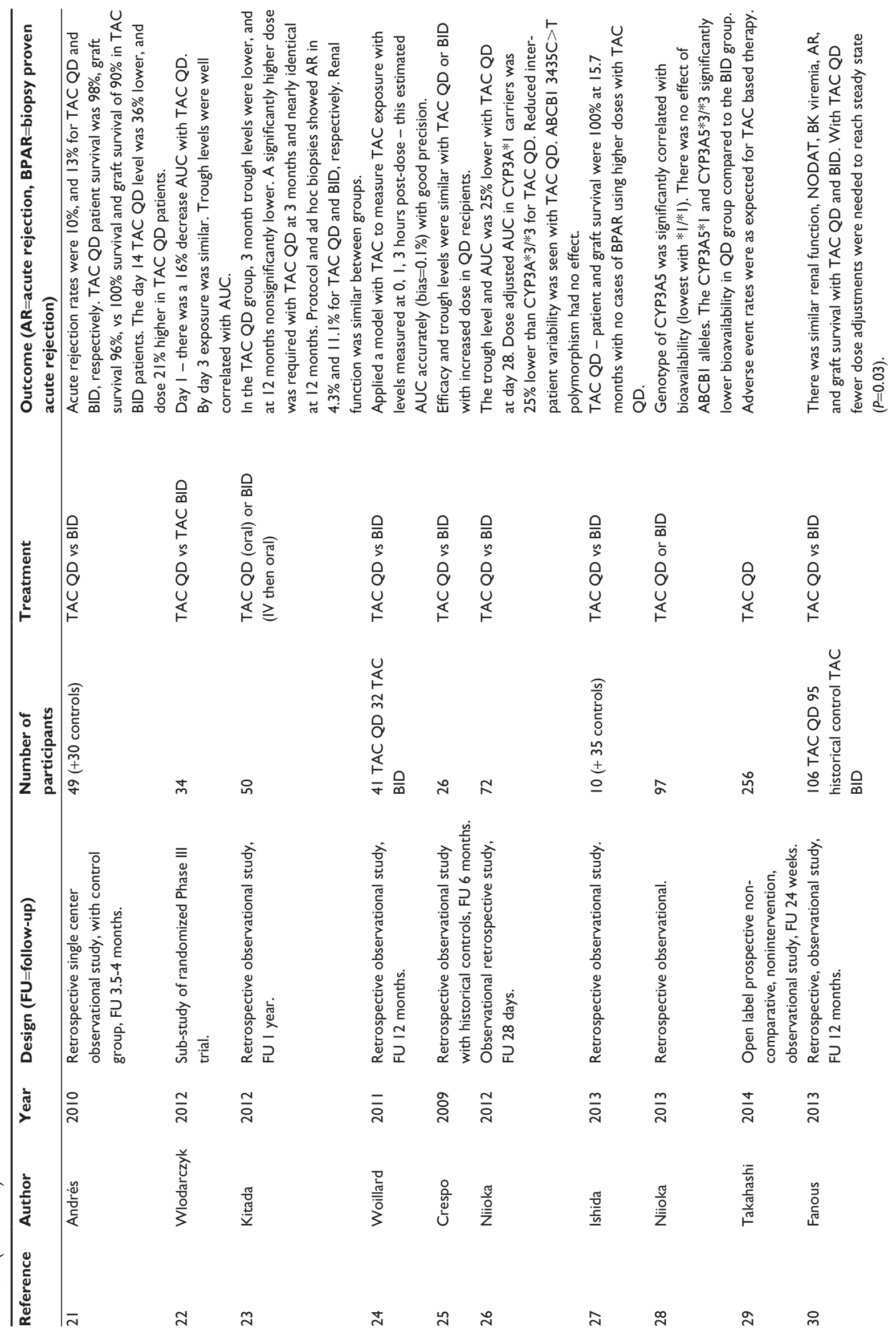




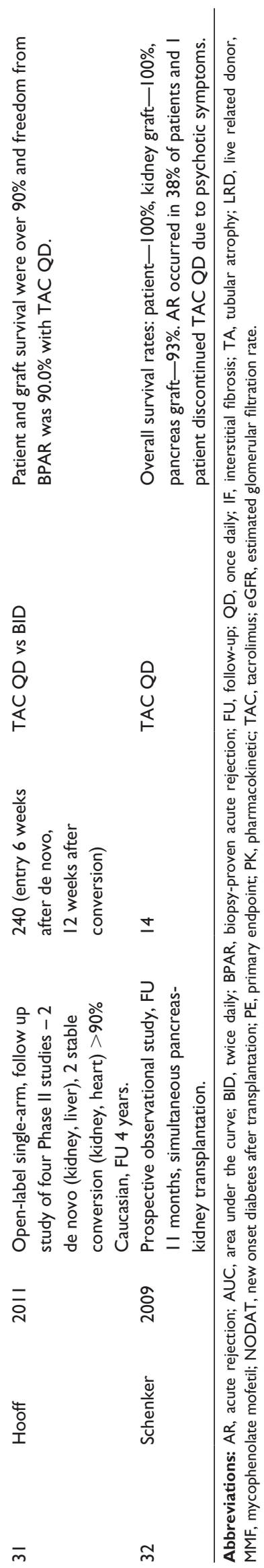

did not reveal any difference in the area under the curve of the drug concentration over time (AUC) or in peak drug levels on day $14 .{ }^{12} \mathrm{~A}$ retrospective study analyzing protocol biopsies in living related donor kidneys for features of CNI toxicity and subclinical rejection up to 12 months posttransplant found no significant differences, but there was a trend to reduced interstitial fibrosis/tubular atrophy. ${ }^{19}$

Adverse events were equally common across TAC BID and QD treatment arms in randomized controlled trials. ${ }^{11-16}$ Specifically, there was no significant difference in indices of glucose metabolism.

The majority of studies where AUC has been assessed have reported that trough levels were highly correlated, and these studies recommend routine clinical monitoring using trough levels. ${ }^{15}$ The manufacturer's recommendation of close monitoring in the first 2 weeks to ensure therapeutic levels is based on a study that showed an initial $30 \%$ lower AUC after the first day..$^{15}$ By day 14 , levels were comparable in TAC QD and TAC BID groups. ${ }^{15}$ One study found that, for patients taking relatively high doses of tacrolimus, the AUC was in a therapeutic range despite subtherapeutic trough levels, indicating that occasional AUC assessment may be useful in routine clinical practice with TAC QD. ${ }^{20}$ Older patients ( $>60$ years old) have been found to require lower doses of TAC QD than younger patients to achieve therapeutic trough levels. ${ }^{21}$

The efficacy and safety data from 14 additional observational studies are consistent with the randomized controlled trial data (Table 1). ${ }^{19-32}$ Although the effect of TAC QD versus TAC BID on adherence in de novo transplantation has not been systematically tested, an industry-sponsored modeling analysis that extrapolated the effect on adherence, as well as outcomes from a literature review of other studies of twiceversus once-daily medication, suggested that, after 5 years, graft survival would be $6.1 \%$ higher in the TAC QD group, which would result in a cost saving of US $\$ 9,411$ per patient over the 5 years. ${ }^{33}$

TAC QD is a useful treatment option that may reduce pill burden in patients adapting to life after transplantation, but an advantage in terms of efficacy or safety has not been demonstrated.

\section{De novo liver transplantation}

The efficacy and safety of TAC QD in patients undergoing liver transplantation was confirmed by a substantial doubleblind randomized controlled trial with 475 participants (Table 2). ${ }^{34}$ Patients were initially treated with tacrolimus (TAC BID or TAC QD) and steroids, with antiproliferative 


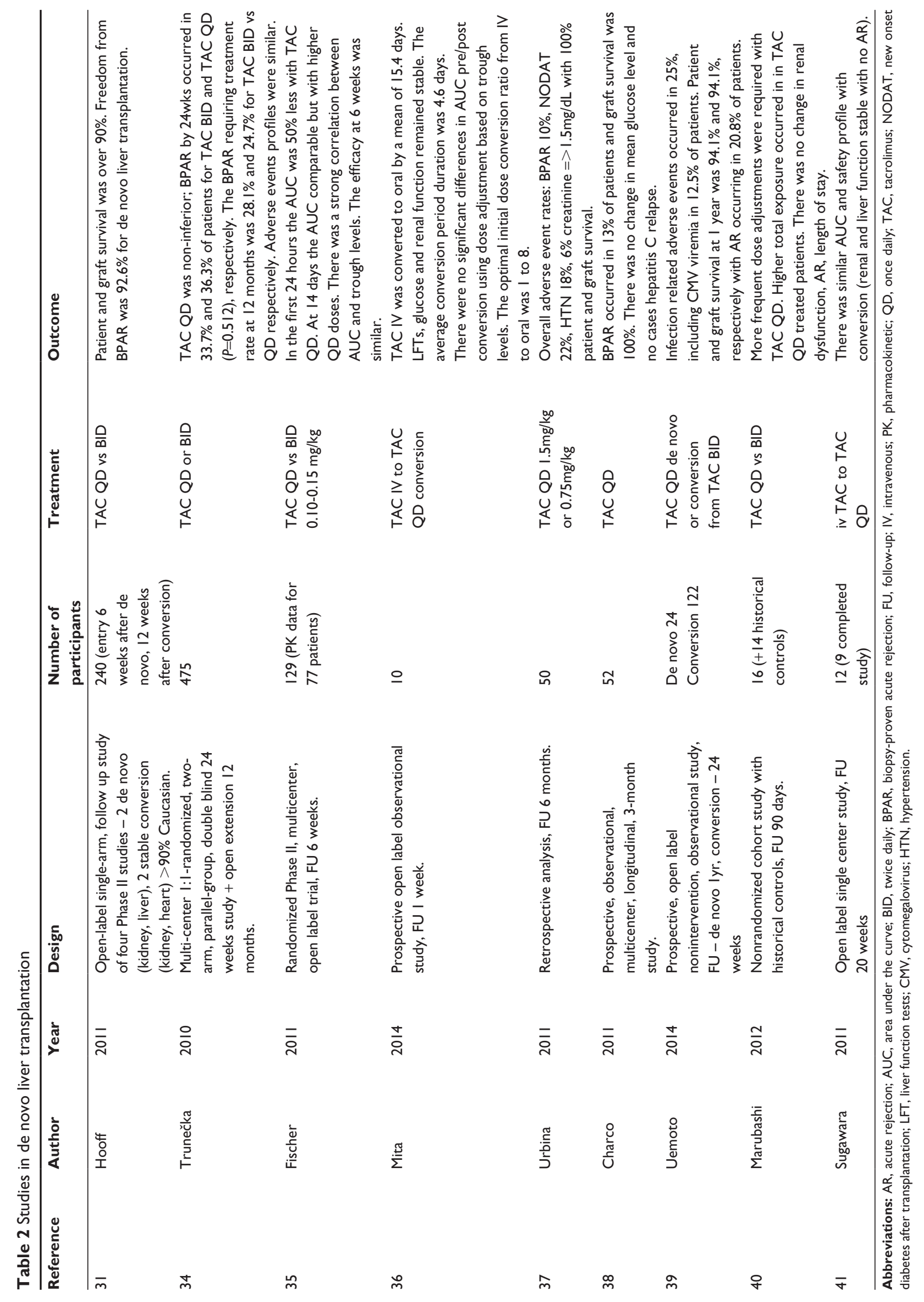


agents allowed only after an acute rejection episode. In this noninferiority study, the primary endpoint of biopsy-proven acute rejection at 24 weeks occurred in $33.7 \%$ of patients receiving TAC BID and $36.3 \%$ of patients receiving TAC QD $(P=0.512)$. Additional follow-up after an open-label extension to 12 months showed similar rates of biopsy-proven acute rejection requiring treatment $(28.1 \%$ and $24.1 \%$ for TAC BID and TAC QD formulations, respectively). In the early postoperative phase, TAC levels were higher in the TAC QD group at day $7(12 \mathrm{ng} / \mathrm{mL}$ versus $9.5 \mathrm{ng} / \mathrm{mL}, P<0.005)$, but patients were initiated on twice the daily total dose of TAC QD due to concerns raised by other studies of reduced exposure in the early phase of TAC QD treatment. No clear correlation between early exposure and biopsy-proven acute rejection was demonstrated. The authors reported that the majority of patients received tacrolimus via nasogastric tube in the postoperative period despite TAC QD consisting of extended release capsules. Nevertheless nasogastric administration did not significantly affect pharmacokinetic profiles. Adverse events were similar between the two groups, although TAC QD was associated with higher mortality than TAC BID in female patients (18.4\% versus $7.8 \%$ ); the cause for this finding remains unclear.

A further randomized open-label trial compared the pharmacokinetic profile and efficacy of TAC QD versus TAC BID in the first 6 weeks after liver transplantation. ${ }^{35}$ Both forms of tacrolimus were administered at a similar starting dose $(0.1-0.15 \mathrm{mg} / \mathrm{kg})$ and this resulted in an AUC that was 50\% lower in TAC QD patients. However, with dose adjustments, a similar AUC was reached by day 14 (TAC QD 324 vs TAC BID 287 ng.h $/ \mathrm{mL}$ ), using a higher mean dose in the TAC QD group. ${ }^{35}$ As with TAC QD usage in de novo kidney transplants, the manufacturer recommends careful monitoring in the first two weeks. At 6 weeks, the AUC was again similar for TAC QD and TAC BID, although TAC QD patients were maintained on a higher dose (TAC QD $0.209 \mathrm{mg} / \mathrm{kg}$; TAC BID $0.165 \mathrm{mg} / \mathrm{kg}$ ) ${ }^{35}$ The secondary endpoints of efficacy and safety were similar in both groups at 6 weeks, with biopsy-proven acute rejection occurring in $26.9 \%$ and $27.4 \%$, respectively. ${ }^{35}$ Patients were not allowed to receive TAC QD by nasogastric tube, but patients in the TAC BID group were allowed to receive the contents of the capsule. In terms of therapeutic drug monitoring for TAC QD, trough levels and AUC were well correlated, allowing routine clinical dose adjustments to be made based on trough levels as for TAC BID. ${ }^{35}$

A smaller study examined the pharmacokinetics of converting intravenous tacrolimus to oral TAC QD, which may be useful for patients who are unable to take oral medication in the immediate postoperative period..$^{36}$ Ten patients received intravenous tacrolimus that was converted to oral TAC QD by a mean of 14.5 days. Conversion was performed gradually over several days and trough-tacrolimus levels were consistently maintained. The authors suggested that the most suitable final dose conversion ratio was 1:8. ${ }^{36}$ The manufacturer has recommended intravenous administration at a fifth of the oral dose.

Other observational studies have yielded similar results regarding efficacy and safety (see Table 2) ${ }^{37-41}$ The effect on long-term adherence of using TAC QD in the immediate postoperative period has not been systematically studied. Several studies examined the effects of TAC QD on metabolic parameters, including glucose metabolism and these were not demonstrably improved compared to patients receiving TAC BID. $31,34,37,38$

In liver transplantation, TAC QD appears similar in efficacy and profile to TAC BID, but a clear advantage has not been demonstrated and clinicians must be careful to avoid low levels in the first few days.

\section{Conversion to TAC QD in stable adult kidney transplant recipients}

The effect of switching to TAC QD in stable kidney-transplant patients has been extensively evaluated in observational crossover studies, but not in randomized controlled trials (Table 3 ). The largest crossover study, involving 1,832 patients, prospectively analyzed the effect of a 1:1 mg for mg conversion (1:1.1 for patients with known low trough levels) on efficacy, safety, and patient satisfaction. ${ }^{42}$ In these patients, the mean trough level was moderately reduced at 12 months $(-9.1 \%)$ and the mean dose was marginally higher $(+1.24 \%) .{ }^{42}$ The persistent reduced level at 12 months raises potential concerns that, over the longer-term, the altered pharmacokinetic profile could increase the risk of subclinical rejection. During the study, TAC QD appeared to be efficacious, with only eight patients developing acute rejection and no overall change in eGFR or proteinuria. ${ }^{42}$ Other cardiovascular and metabolic parameters also remained unchanged, including blood pressure, lipids, glucose, and liver function tests. ${ }^{42}$ Overall $99.4 \%$ of patients preferred once-daily tacrolimus and the discontinuation rate was only $1.9 \% .{ }^{42}$ Other smaller studies have generally been consistent with these results and, most notably, variously show modest reductions in tacrolimus trough levels with no apparent effect on acute rejection (see Table 3), with follow-up ranging from several weeks to 4 years. ${ }^{18,31,43-75}$ 


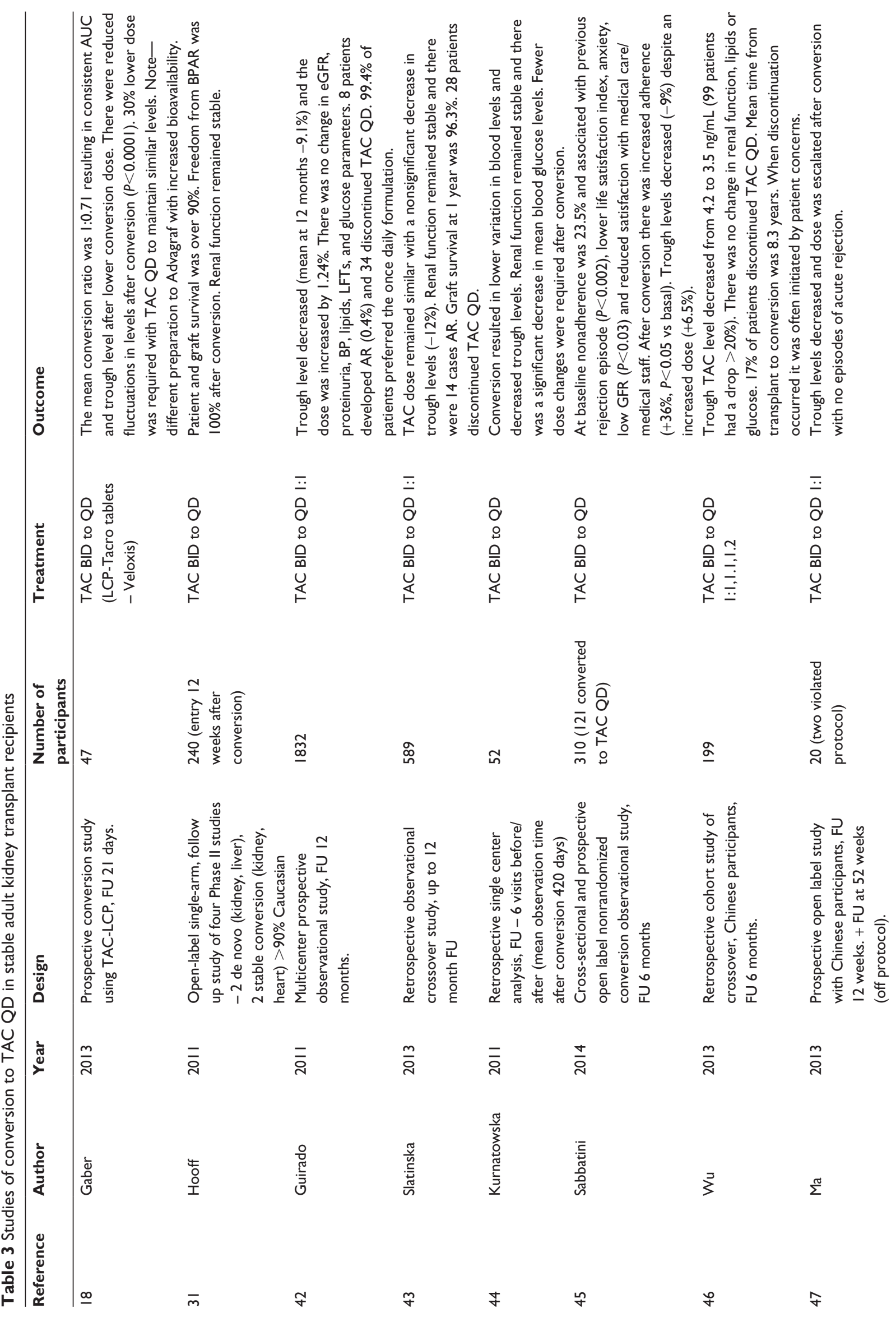




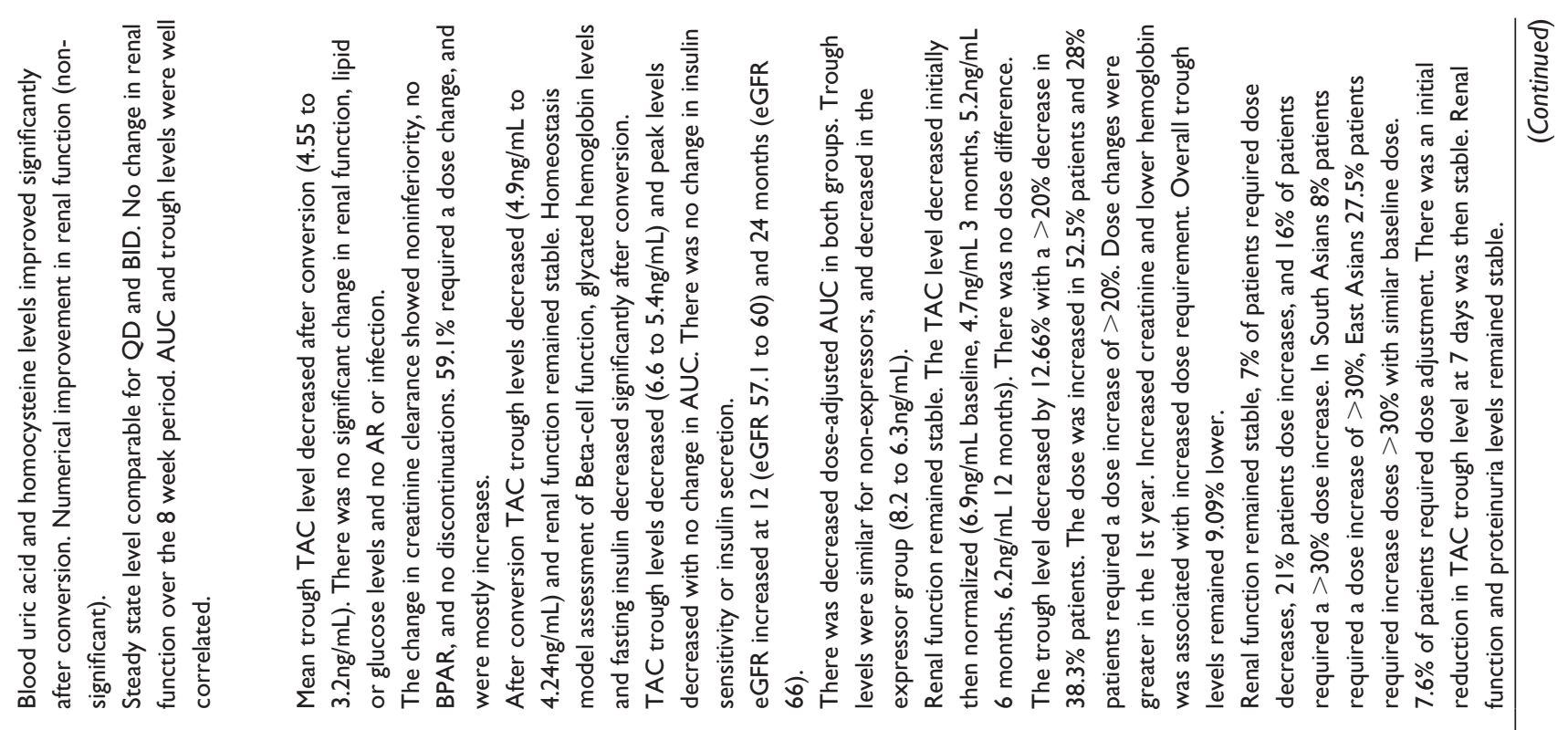

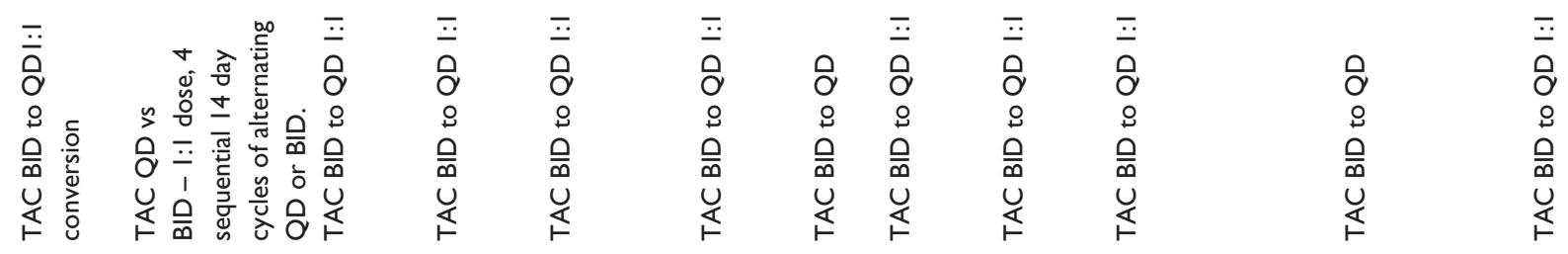

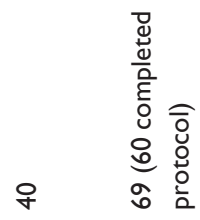
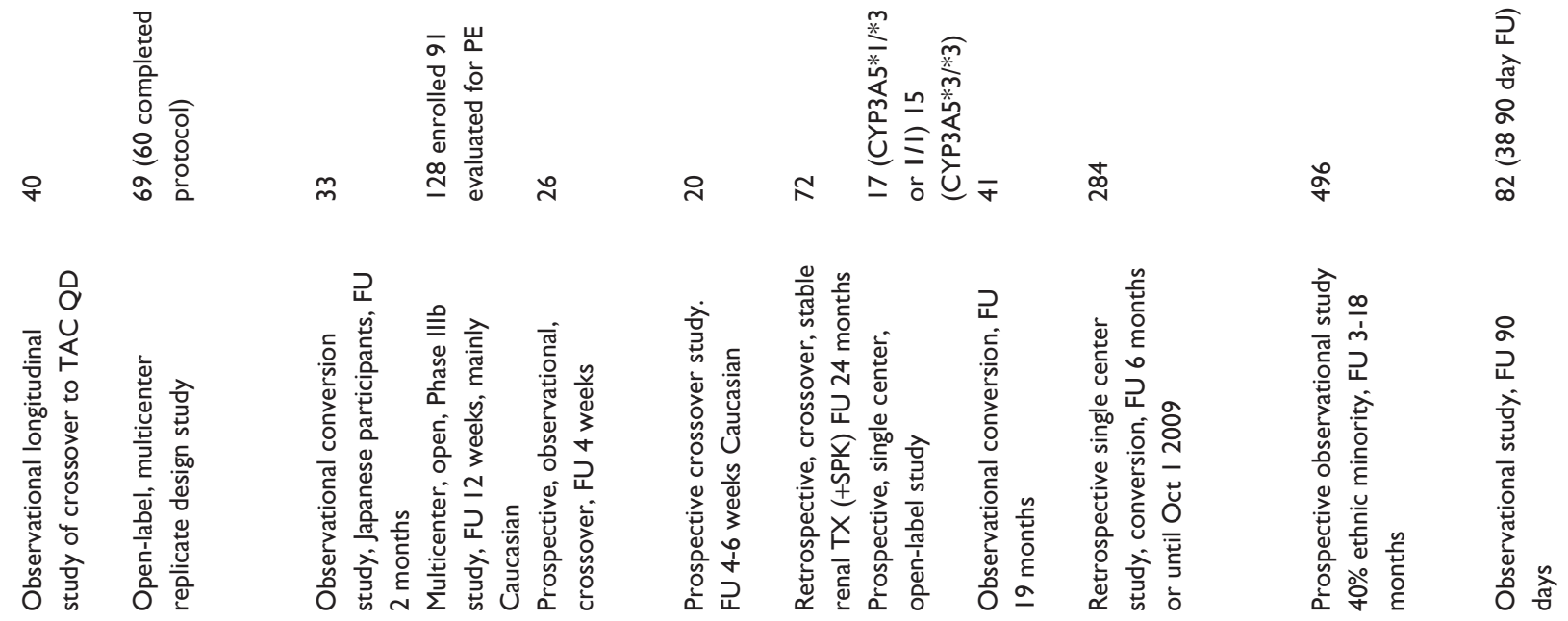

$\frac{9}{4} \quad \frac{9}{4}$

$\frac{4}{2} \frac{9}{4}$

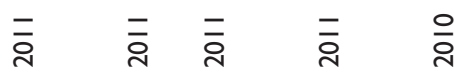

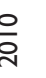

$\frac{4}{8}$

ఫे

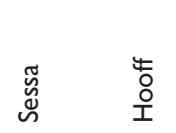

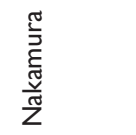

ปั

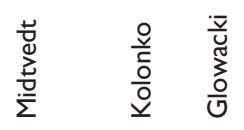

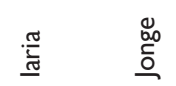

$\stackrel{-100}{\circ}$

$\frac{\breve{\underline{u}}}{\overline{\underline{u}}}$

$\stackrel{\check{0}}{0}$

$\stackrel{o}{q}$

으 든

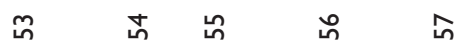

$\stackrel{\infty}{n}$

in 


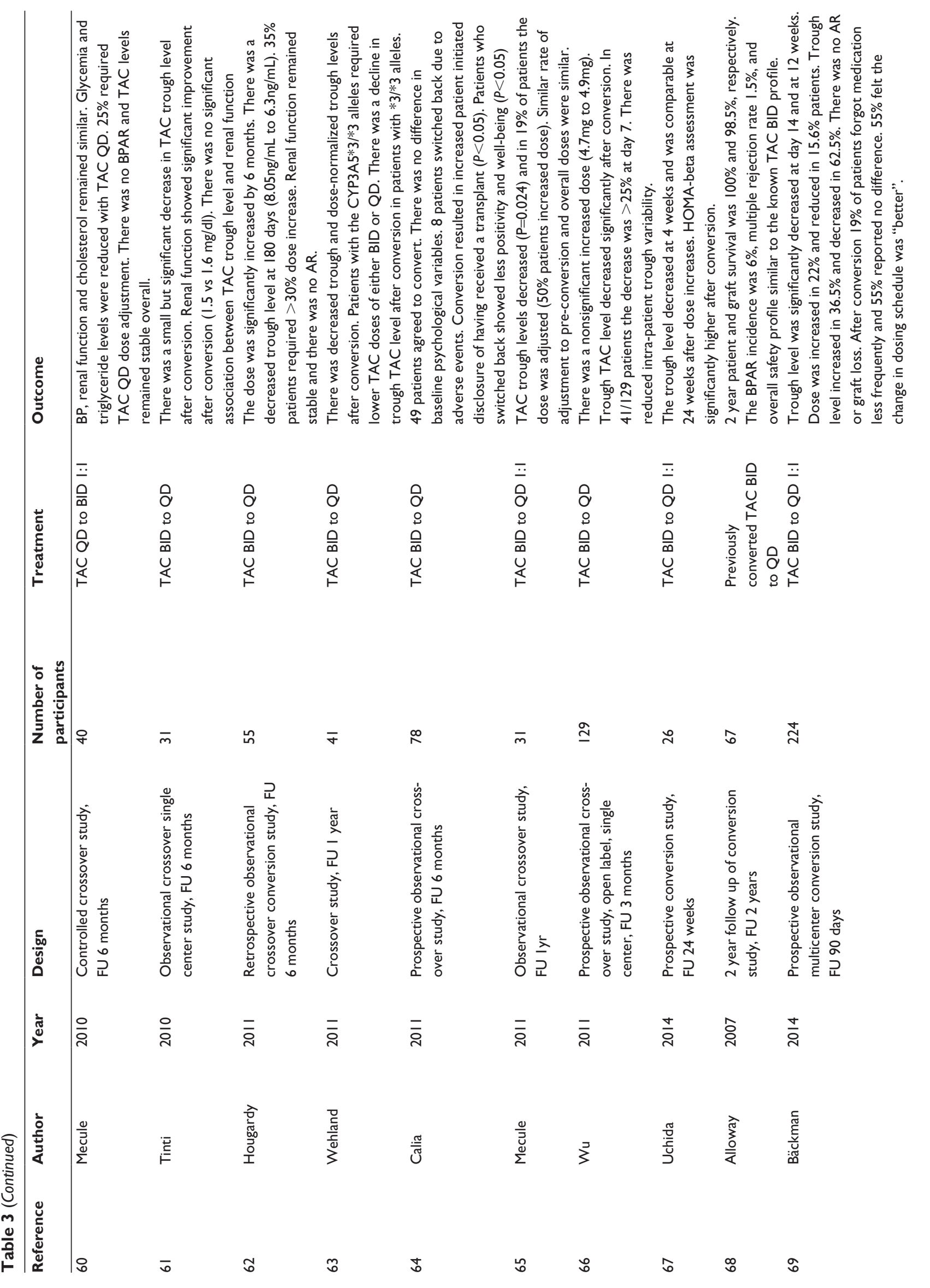



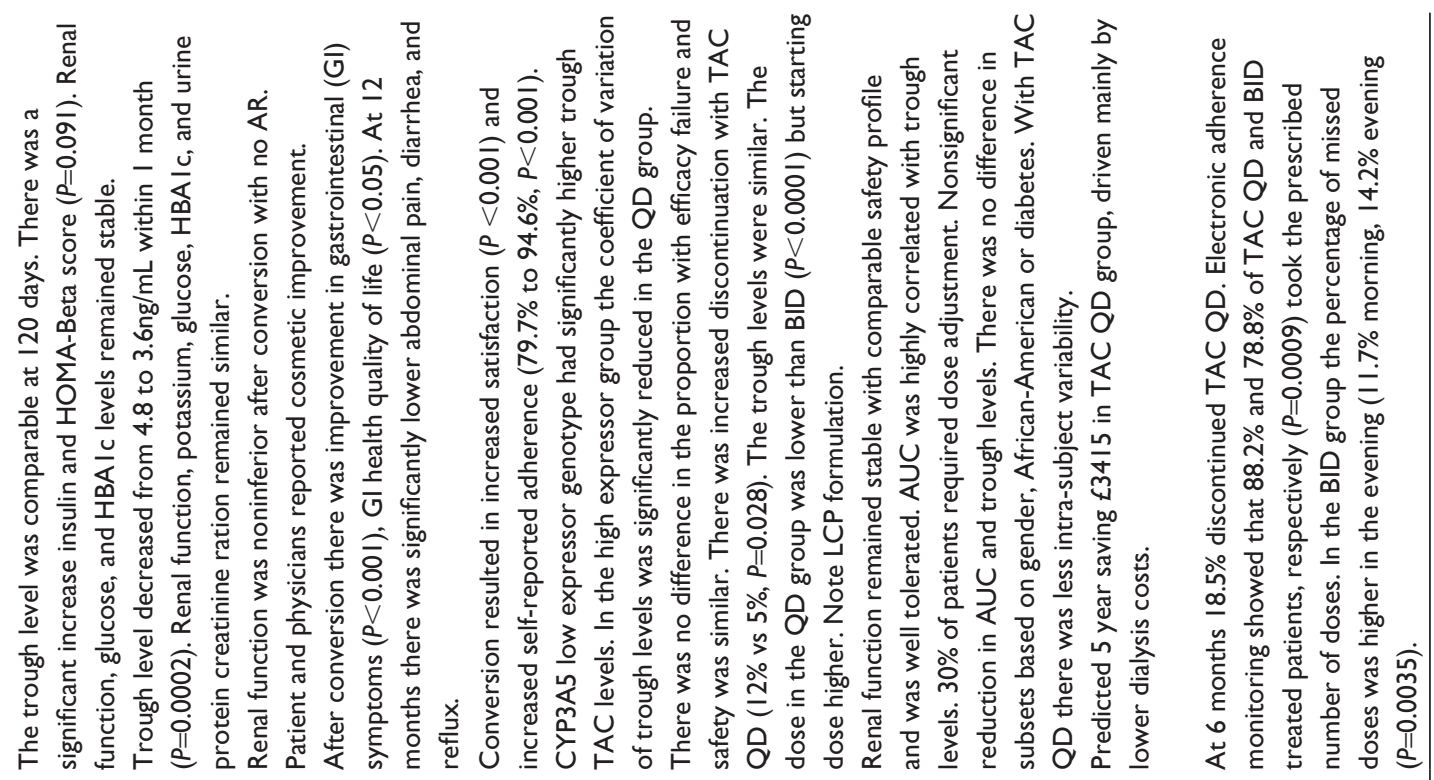

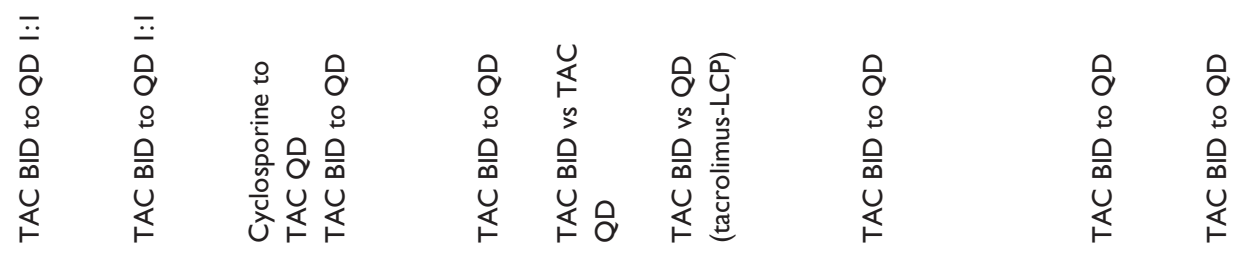
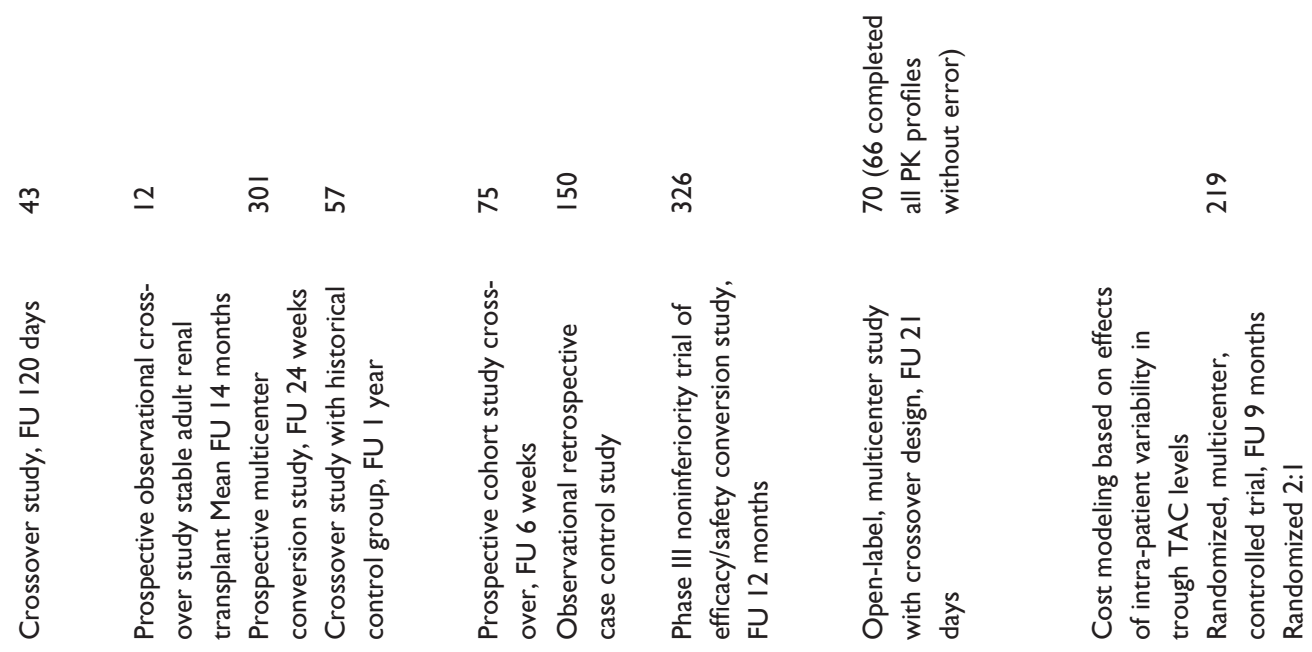

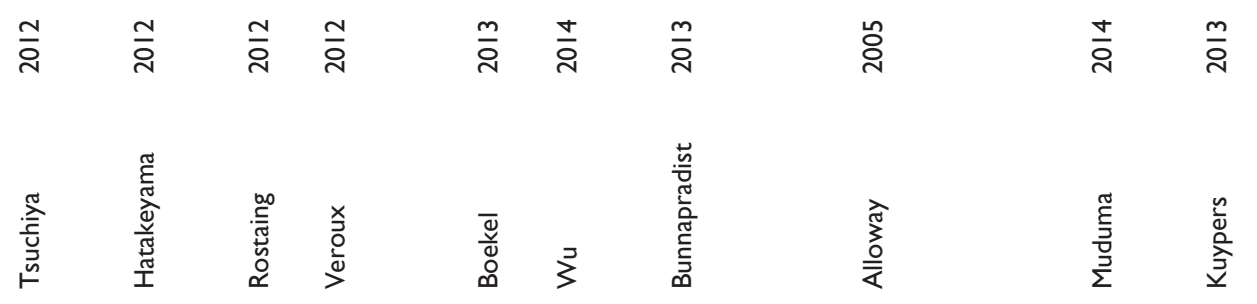

$5 \pi N \frac{1}{5} \pi$

R

$\stackrel{\infty}{\wedge}$

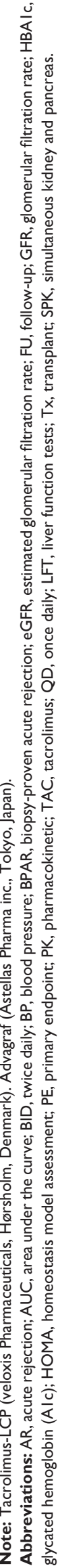


One study reported improved fasting blood glucose levels with TAC QD (103.4 mg/dL versus $95 \mathrm{mg} / \mathrm{dL}, P<0.03)$, but this may be in keeping with reduced trough levels in the TAC QD group. ${ }^{44}$ Another once-daily tacrolimus preparation under development that has a different pharmacokinetic profile, Tacrolimus-LCP, showed noninferiority to TAC BID in a randomized Phase III conversion study. ${ }^{76}$

The pharmacokinetic profile within 21 days of switching to TAC QD was studied in detail in 66 patients. ${ }^{77}$ As with other patient groups receiving TAC QD, trough levels were highly correlated with AUC - a finding that supports routine clinical monitoring. A nonsignificant reduction in AUC and trough level was observed, but only $30 \%$ of patients required a dose change. ${ }^{77}$ The manufacturer recommends a $1: 1 \mathrm{mg}$ for mg conversion of the total daily dose and also checking of a level prior to and within 2 weeks of conversion. As has subsequently be observed in other studies, there was less intrasubject variability in tacrolimus levels - a factor that, in a model-based analysis, was predictive of reductions in graft failure and consequent dialysis costs. ${ }^{78}$

The effect of tacrolimus conversion on adherence has been assessed in a randomized controlled trial that used electronic recordings of pill bottle opening as an indirect objective measure, coupled with subjective questionnaire interviews. ${ }^{79}$ Two hundred and nineteen stable patients were randomized to TAC QD or continuation of TAC BID and followed for 3 months prior to conversion as well as 6 months after. ${ }^{79}$ At 6 months, persistence with the prescribed regimen was higher for TAC QD ( $81.5 \%$ versus $71.9 \%, P=0.0824) .{ }^{79}$ The number of patients taking the prescribed number of daily doses was significantly higher for TAC QD $(88.2 \%$ versus $78.8 \%$, $P=0.0009) .{ }^{79}$ In keeping with data from other studies, patients were less adherent with the evening dose of TAC BID (missed doses: $11.7 \%$ morning versus $14.2 \%$ evening, $P=0.0035){ }^{79}$ Adherence was also improved after conversion in several observational crossover studies using questionnaires, and no study found decreased adherence. ${ }^{42,45}$ However, despite this success, another study found a high discontinuation rate after conversion in patients who were about 8 years out from transplantation. ${ }^{46}$ Discontinuation was primarily due to patient concerns and anxiety, presumably due to their aversion to changing from a long established and effective treatment. ${ }^{46}$

Overall, despite the lack of randomized controlled trials studying the efficacy and safety of conversion to TAC QD, the plethora of observational conversion studies support TAC QD as a broadly equivalent treatment in terms of relatively short-term outcomes. However, the modest but persistently reduced levels found in some studies require long-term follow-up data to analyze the effects on subclinical rejection and increased chronic allograft nephropathy and, conversely, on drug-induced nephrotoxicity.

\section{Conversion to TAC QD in stable adult liver transplant recipients}

We identified 17 studies examining the effects of conversion from TAC BID to TAC QD in stable liver transplant recipients (Table 4)..$^{39,69,80-94}$ The majority of the studies were observational crossover studies examining pharmacokinetic profiles and efficacy in patients before and after conversion. We did not identify randomized or blinded controlled trials. In almost all studies, a 1:1 mg for mg conversion of tacrolimus was used. In the majority of the 17 studies, tacrolimus levels were reduced after 1:1 conversion, but tended to normalize back to preconversion levels after physician-initiated dose increases in a subset of patients. ${ }^{69,80-86}$ However, this finding was not universal across all studies and, even in studies showing an initial mean decrease in trough levels, a subset of patients had higher levels after conversion. ${ }^{69,87} \mathrm{~A}$ detailed open-label multicenter prospective study investigated the pharmacokinetic effect of crossover using a four-period crossover design in which patients received TAC BID and TAC QD in alternating 14 day blocks. ${ }^{88}$ Importantly, as with studies in de novo liver transplants, the AUC and trough levels were highly correlated, which supports routing clinical drug level monitoring using trough levels. Overall, after treatment with TAC QD, there was a nonsignificant $11.1 \%$ reduction in tacrolimus levels. Eighty percent of patients did not require a dose change and there was less intrapatient variability in tacrolimus levels during TAC QD treatment. At 2-years follow-up of 56 patients maintained on TAC QD, the biopsy-proven acute rejection incidence was $5.6 \%$, and the rates of infectious and metabolic complications were similar to those expected with TAC BID. ${ }^{91}$ Across these observational studies, there was no evidence of increased rejection rates despite initial reductions in trough levels in some patients, but no study had a follow-up of more than 2 years. In one study, renal function was significantly improved after conversion, with the MDRD eGFR rising from 71 to $82 \mathrm{~mL} / \min (P=0.001)$, but there was no control arm. ${ }^{86} \mathrm{~A}$ change back from TAC QD to TAC BID was infrequent; a 24 month retrospective study of 394 patients found that only 16 patients switched back to TAC BID for various reasons, the commonest being tremor $(n=3){ }^{85}$ Taken together, these data suggest that conversion to TAC QD is safe and efficacious. Since the effects on trough levels after conversion vary across individuals, robust monitoring may be required for the first few weeks to months to individualize dose levels. ${ }^{85}$ 


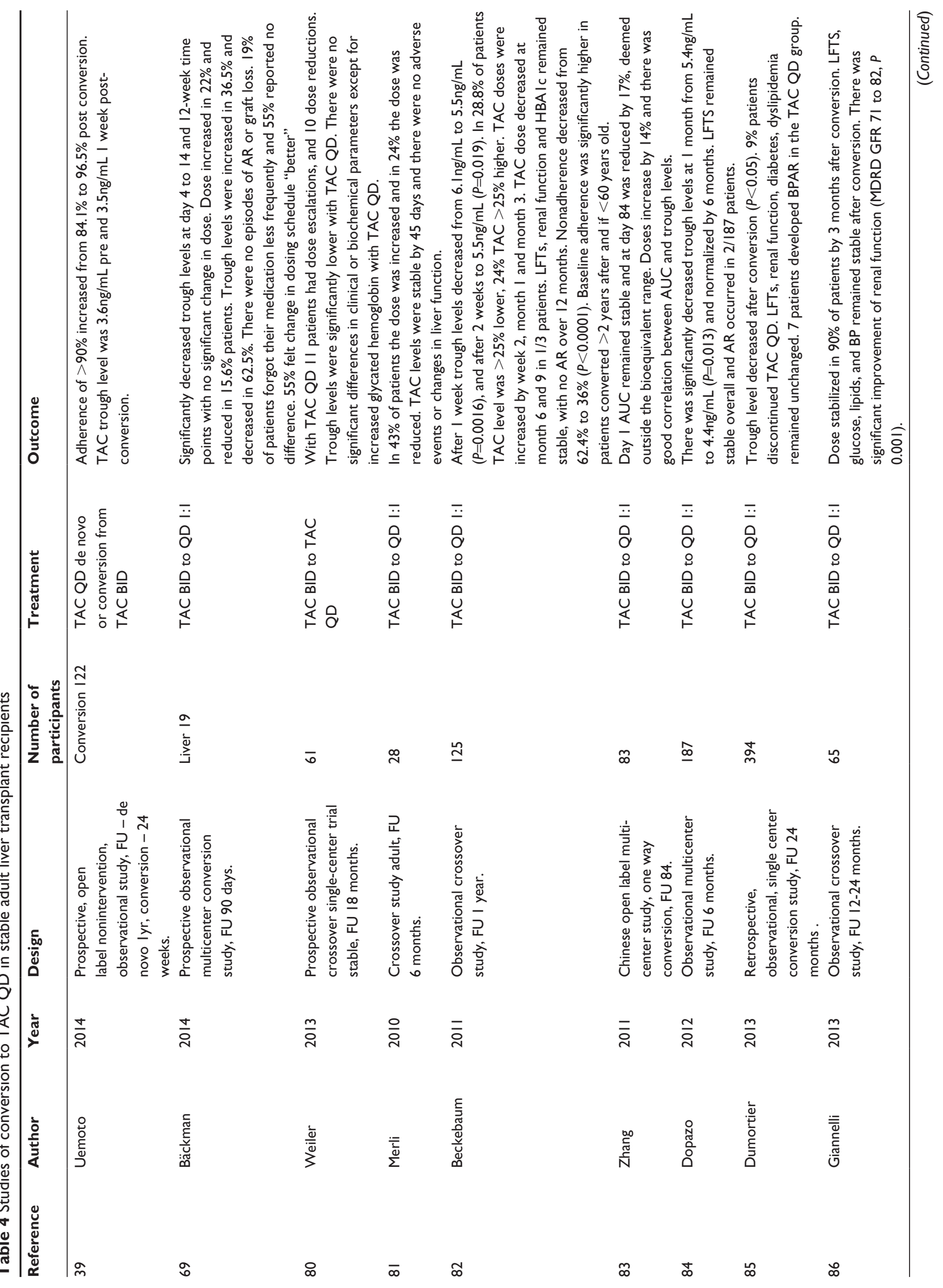




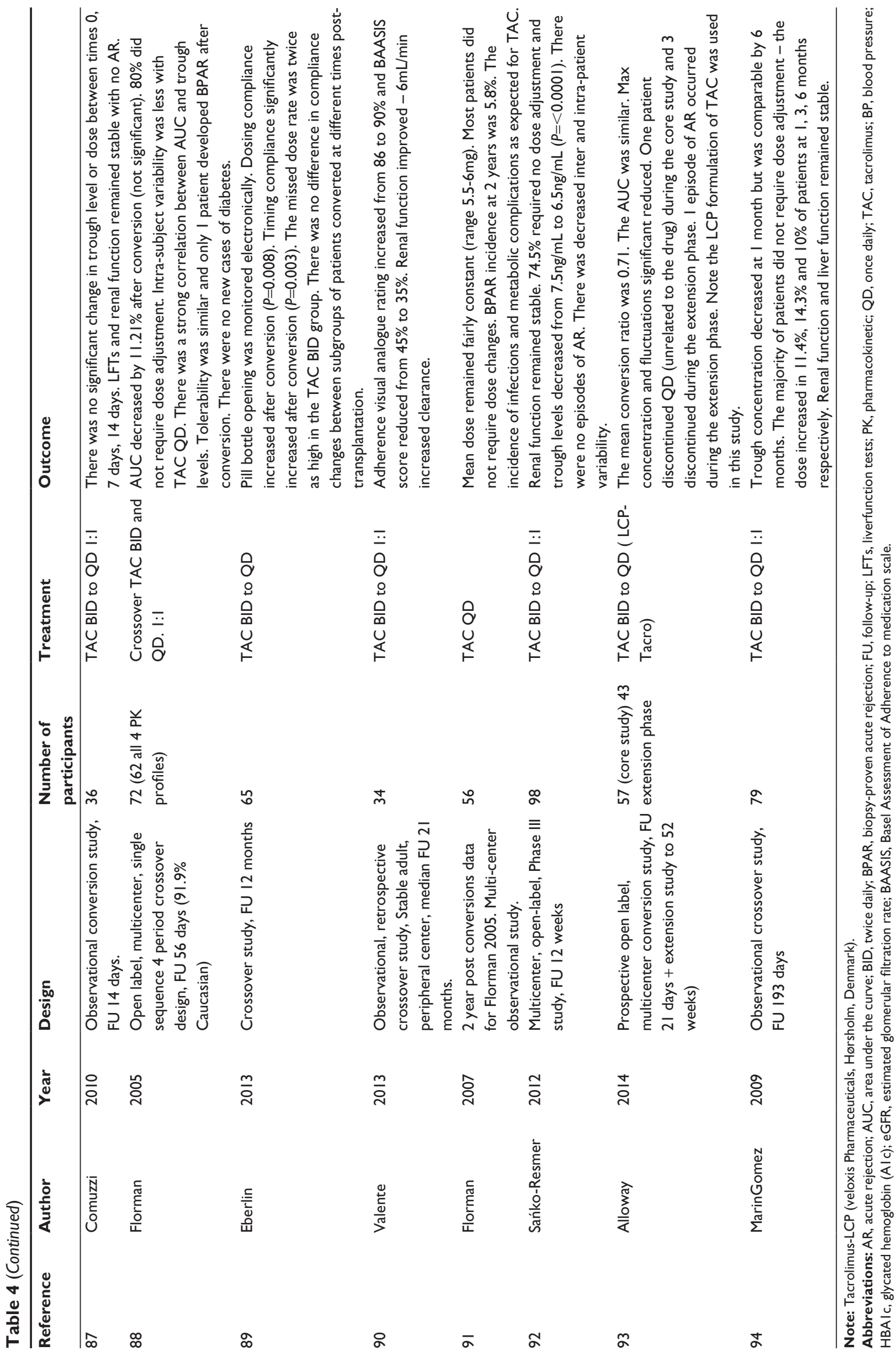


Adherence to TAC QD was assessed in four of the 18 studies. ${ }^{39,69,82,89}$ Adherence was improved in three studies $^{39,82,89}$ and was relatively unchanged in one study. ${ }^{69}$ One study measured electronic pill bottle opening and found that both dosing compliance and timing compliance were significantly improved after the conversion $(P=0.008$ and 0.003 , respectively). ${ }^{89}$ The missed-dose rate was twice as high in the TAC BID group. ${ }^{89}$ The beneficial effect on adherence was present in patients converted relatively soon after ( 6 months to 2 years), during an intermediate period after (2-5 years), and over 5 years after transplantation. Overall, the absolute benefit in adherence with TAC QD was limited since the median compliance level in patients receiving TAC BID was already over $95 \% .{ }^{89}$ Subjective quality of life scores were improved in patients taking TAC QD. ${ }^{89}$ Overall, these studies suggest a moderate improvement in already high levels of adherence, but they lack randomized control arms. Furthermore, poorly adherent patients may be underrepresented as recruits to studies of stable patients, so it remains unclear whether TAC QD provides a significant benefit to unstable patients. A causal effect on improved outcomes has not yet been assessed, but may be extrapolated from other studies. Importantly, omitting a dose of a once-daily regimen could be more damaging than omitting a dose of a twice-daily regimen.

\section{Simultaneous pancreas kidney transplantation}

One prospective study of 14 de novo simultaneous pancreas kidney patients showed patient, kidney, and pancreas survival at 11 months follow-up of $100 \%, 100 \%$, and $93 \%$, respectively. ${ }^{32}$ One pancreas was lost 2 days postoperatively due to vascular graft thrombosis. Interestingly, drug levels declined in weeks $2-3$, and the authors commented that patients sometimes required substantial doses and that drug levels responded slowly to dose changes. They suggested that there might be a different pharmacokinetic profile in simultaneous pancreas kidney transplantation due to enteric drainage or improvements in gastroparesis. ${ }^{32}$ This could be further dissected by analyzing pharmacokinetic data in patients with bladder drainage of exocrine secretions.

\section{Specific effects on glucose metabolism}

Tacrolimus causes a dose-dependent decrease in insulin secretion, and some studies have indicated that tacrolimus has a stronger association with new-onset diabetes after transplantation (NODAT) compared to cyclosporine. Since high peak concentrations are associated with impaired glucose metabolism, there has been interest in whether the pharmacokinetics ofTAC QD improve glucose metabolism. Although most conversion studies have not reported any change in glucose metabolism or NODAT, they had not used the gold standard technique for investigating glucose metabolism. A study using the gold standard glucose clamp technique before and after conversion to TAC QD in stable renal transplants did not find any significant change in insulin sensitivity despite reduced tacrolimus peak and trough levels (no difference in AUC was observed). ${ }^{53}$ The authors concluded that switching to TAC QD was not an evidenced treatment for patients developing NODAT, though they did not study this patient group. ${ }^{53}$ A specific effect on glucose metabolism was examined in a short 4 week prospective study of 26 patients switching from TAC BID to TAC QD with a $1: 1$ dose conversion. ${ }^{52}$ Four weeks after conversion, there was an improvement in pancreatic islet beta-cell function and glycated hemoglobin levels. ${ }^{52}$ These effects were considered secondary to reduced trough levels of TAC QD after conversion. ${ }^{52}$ Reduced blood glucose levels were observed in 52 stable renal-transplant patients converted to TAC QD $(103.4 \mathrm{mg} / \mathrm{dL}$ versus $95 \mathrm{mg} / \mathrm{dL}, P<0.03)$ in association with reduced trough TAC levels. ${ }^{44}$ A small crossover study with a control group found that TAC QD was associated with improved glucose and triglyceride levels as well as trough drug levels that were nonsignificantly lower after conversion. ${ }^{60}$

\section{Genetic effects on pharmacokinetics}

Tacrolimus is metabolized by CYP3A5, a member of the cytochrome P450 superfamily of enzymes. Individuals vary in their expression of functional CYP3A5 protein. The CYP3A5*1 allele results in expression of an mRNA that encodes a functional enzyme, and individuals possessing this allele are termed "expressors". The CYP3A5* allele results in an mRNA with a premature stop codon, and individuals with these alleles are termed "non-expressors". TAC QD levels are altered by CYP3A5 expressor status such that the CYP3A $5 * 1 / * 1$ genotype has been associated with trough levels that are $25 \%$ lower than those seen with the CYP $3 A * 3 / * 3$ genotype. ${ }^{26,28}$ Homozygotes for the CYP3A5*1 allele had an increased risk of acute rejection $(P=0.01)$ in some studies of patients treated with TAC BID. ${ }^{95}$ Future studies may investigate whether genotyping kidney transplant recipients or liver donors alters clinically meaningful outcomes.

\section{Conclusion}

Over the last 10 years, tacrolimus has become the most popular CNI for preventing allograft rejection. The availability of 
a once-daily form represents has the potential to improve adherence. It is evident from studies lasting up to 2 years in both liver and kidney recipients that TAC QD is broadly equivalent in efficacy and side effects. However, no clear benefits have been demonstrated for hard clinical outcomes and problems such as dose-related effects on insulin secretion remain. Nevertheless, a strong literature exists for the role of nonadherence in graft loss, and modestly improving adherence by concomitantly easing the pill burden could be beneficial. Effects on outcomes arising from improved compliance will require long-term data in large numbers of patients. From a practical perspective, clinicians need to recognize the potential for lower drug levels compared to TAC BID in the first few weeks of starting or converting to TAC QD. For this reason, when converting from TAC BID to TAC QD, consideration should be given to increasing the overall dose by $10 \%-15 \%$. However, since predictive criteria for interpatient dose responses remain unknown, only careful monitoring can ensure therapeutic levels. There remains a potential concern that, in some studies, trough levels have been persistently lower and could impact on graft function in the long-term, but there may be reciprocal benefits from reduced nephrotoxicity.

\section{Disclosure}

The authors report no conflicts of interest in this work.

\section{References}

1. Matas AJ, Smith JM, Skeans MA, et al. OPTN/SRTR 2012 Annual Data Report: Kidney. Am J Transplant. 2014;14:11-44.

2. Jensik SC. Tacrolimus (FK 506) in kidney transplantation: three-year survival results of the US multicenter, randomized, comparative trial. FK 506 Kidney Transplant Study Group. Transplant Proc. 1998;30: 1216-1218.

3. Johnson C, Ahsan N, Gonwa T, et al. Randomized trial of tacrolimus (Prograf) in combination with azathioprine or mycophenolate mofetil versus cyclosporine (Neoral) with mycophenolate mofetil after cadaveric kidney transplantation. Transplantation. 2000;69:834-841.

4. Vincenti F, Jensik SC, Filo RS, Miller J, Pirsch J. A long-term comparison of tacrolimus (FK506) and cyclosporine in kidney transplantation: evidence for improved allograft survival at five years. Transplantation. 2002;73:775-782.

5. Pirsch JD, Miller J, Deierhoi MH, Vincenti F, Filo RS. A comparison of tacrolimus (FK506) and cyclosporine for immunosuppression after cadaveric renal transplantation. FK506 Kidney Transplant Study Group. Transplantation. 1997;63:977-983.

6. Kim WR, Smith JM, Skeans MA, et al. OPTN/SRTR 2012 Annual Data Report: liver. Am J Transplant. 2014;14 Suppl 1:69-96.

7. Denhaerynck K, Dobbels F, Cleemput I, et al. Prevalence, consequences, and determinants of nonadherence in adult renal transplant patients: a literature review. Transpl Int. 2005;18:1121-1133.

8. Butler JA, Roderick P, Mullee M, Mason JC, Peveler RC. Frequency and impact of nonadherence to immunosuppressants after renal transplantation: a systematic review. Transplantation. 2004;77:769-776.

9. Dew MA, Dabbs AD, Myaskovsky L, et al. Meta-analysis of medical regimen adherence outcomes in pediatric solid organ transplantation. Transplantation. 2009;88:736-746.
10. Claxton AJ, Cramer J, Pierce C. A systematic review of the associations between dose regimens and medication compliance. Clin Ther. 2001;23: 1296-1310.

11. Albano L, Banas B, Klempnauer JL, et al. OSAKA trial: a randomized, controlled trial comparing tacrolimus QD and BD in kidney transplantation. Transplantation. 2013;96:897-903.

12. Tsuchiya $\mathrm{T}$, Ishida $\mathrm{H}$, Tanabe $\mathrm{T}$, et al. Comparison of pharmacokinetics and pathology for low-dose tacrolimus once-daily and twice-daily in living kidney transplantation: prospective trial in once-daily versus twice-daily tacrolimus. Transplantation. 2013;96:198-204.

13. Krämer BK1, Charpentier B, Bäckman L, et al. Tacrolimus once daily (ADVAGRAF) versus twice daily (PROGRAF) in de novo renal transplantation: a randomized phase III study. Am J Transplant. 2010;10:2632-2643.

14. Cabello M, García P, González-Molina M, et al. Pharmacokinetics of once- versus twice-daily tacrolimus formulations in kidney transplant patients receiving expanded criteria deceased donor organs: a singlecenter, randomized study. Transplant Proc. 2010;42:3038-3040.

15. Wlodarczyk Z, Squifflet JP, Ostrowski M, et al. Pharmacokinetics for once- versus twice-daily tacrolimus formulations in de novo kidney transplantation: a randomized, open-label trial. Am J Transplant. 2009;9:2505-2513.

16. Silva HT Jr, Yang HC, Abouljoud M, et al. One-year results with extendedrelease tacrolimus/MMF, tacrolimus/MMF and cyclosporine/MMF in de novo kidney transplant recipients. Am J Transplant. 2007;7:595-608.

17. Ho ET, Wong G, Craig JC, Chapman JR. Once-daily extendedrelease versus twice-daily standard-release tacrolimus in kidney transplant recipients: a systematic review. Transplantation. 2013; 95:1120-1128.

18. Alloway RM, Mulgaonkar S, Ueda K, Cohen D, Kaplan B. A phase 2 randomized study of the pharmacokinetics, safety and efficacy of LCPTacro tablets once-a-day vs Prograf capsules twice-a-day in de novo kidney transplants. Am J Transplant. Volume 11, Issue Supplement s2, pages 213-527. Conference: April, 2011.

19. Masutani K, Tsuchimoto A, Haruyama N, et al. Protocol biopsy findings in living donor kidney transplant patients treated with once-daily or twicedaily tacrolimus formulation. Transplant Proc. 2014;46: 395-399.

20. Jelassi ML, Lefeuvre S, Karras A, Moulonguet L, Billaud EM. Therapeutic drug monitoring in de novo kidney transplant receiving the modifiedrelease once-daily tacrolimus. Transplant Proc. 2011;43:491-494.

21. Andrés A, Delgado-Arranz M, Morales E, et al. Extended-release tacrolimus therapy in de novo kidney transplant recipients: single-center experience. Transplant Proc. 2010;42:3034-3037.

22. Wlodarczyk Z, Ostrowski M, Mourad M, et al. Tacrolimus pharmacokinetics of once- versus twice-daily formulations in de novo kidney transplantation: a substudy of a randomized phase III trial. Ther Drug Monit. 2012;34:143-147.

23. Kitada H, Okabe Y, Nishiki T, et al. One-year follow-up of treatment with once-daily tacrolimus in de novo renal transplant. Exp Clin Transplant. 2012;10:561-567.

24. Woillard JB, de Winter BC, Kamar N, Marquet P, Rostaing L, Rousseau A. Population pharmacokinetic model and Bayesian estimator for two tacrolimus formulations - twice daily Prograf and once daily Advagraf. Br J Clin Pharmacol. 2011;71:391-402.

25. Crespo M, Mir M, Marin M, et al. De novo kidney transplant recipients need higher doses of Advagraf compared with Prograf to get therapeutic levels. Transplant Proc. 2009;41:2115-2117.

26. Niioka T, Satoh S, Kagaya H, et al. Comparison of pharmacokinetics and pharmacogenetics of once- and twice-daily tacrolimus in the early stage after renal transplantation. Transplantation. 2012;94:1013-1019.

27. Ishida K, Ito S, Tsuchiya T, Imanishi Y, Deguchi T. Clinical experience with once-daily tacrolimus in de novo kidney transplant recipients from living donors in Japan: 1-year follow up. Cent European J Urol. 2013;66:344-349.

28. Niioka T, Kagaya H, Miura M, et al. Pharmaceutical and genetic determinants for interindividual differences of tacrolimus bioavailability in renal transplant recipients. Eur J Clin Pharmacol. 2013;69:1659-1665. 
29. Takahashi K, Abe R, Usuki S, So M. Safety and efficacy of once-daily modified-release tacrolimus in kidney transplant recipients: interim analysis of multicenter postmarketing surveillance in Japan. Transplant Proc. 2014;46:406-410.

30. Fanous H, Zheng R, Campbell C, et al. A comparison of the extendedrelease and standard-release formulations of tacrolimus in de novo kidney transplant recipients: a 12-month outcome study. Clin Kidney J. 2013;6:45-49.

31. van Hooff JP, Alloway RR, Trunečka P, Mourad M. Four-year experience with tacrolimus once-daily prolonged release in patients from phase II conversion and de novo kidney, liver, and heart studies. Clin Transplant. 2011;25:E1-E12.

32. Schenker P, Klein T, Kruger B, et al. Modified release tacrolimus in de novo immunosuppression after simultaneous pancreas-kidney transplantation - a first single-center experience. Transplant Proc. 2009;41:2573-2575.

33. Abecassis MM, Seifeldin R, Riordan ME. Patient outcomes and economics of once-daily tacrolimus in renal transplant patients: results of a modeling analysis. Transplant Proc. 2008;40:1443-1445.

34. Trunečka P, Boillot $\mathrm{O}$, Seehofer $\mathrm{D}$, et al. Once-daily prolonged-release tacrolimus (ADVAGRAF) versus twice-daily tacrolimus (PROGRAF) in liver transplantation. Am J Transplant. 2010;10:2313-2323.

35. Fischer L, Trunečka P, Gridelli B, et al. Pharmacokinetics for once-daily versus twice-daily tacrolimus formulations in de novo liver transplantation: a randomized, open-label trial. Liver Transpl. 2011;17:167-177.

36. Mita A, Ikegami T, Masuda Y, et al. Optimal initial dose of orally administered once-daily extended-release tacrolimus following intravenous tacrolimus therapy after liver transplantation. Transplant Proc. 2014;46:794-796.

37. Ortiz de Urbina J, Valdivieso A, Matarranz A, et al. Advagraf de novo in liver transplantation: a single-center experience. Transplant Proc. 2011;43:724-725

38. Charco R, Caralt M, Llado L, et al. A prospective, multicenter study of once-daily extended-release tacrolimus in de novo liver transplant recipients. Transplantat Proc. 2011;43:718-723.

39. Uemoto S, Abe R, Horike H, So M. Safety and efficacy of once-daily modified-release tacrolimus in liver transplant recipients: a multicenter postmarketing surveillance in Japan. Transplant Proc. 2014;46: 749-753.

40. Marubashi S, Wada H, Kobayashi S, et al. Once-daily prolonged-release tacrolimus in de novo liver transplantation: a single center cohort study. Hepatogastroenterology. 2012;59:1184-1188.

41. Sugawara Y, Miyata Y, Kaneko J, et al. Once-daily tacrolimus in living donor liver transplant recipients. Biosci Trends. 2011;5:156-158.

42. Guirado L, Cantarell C, Franco A, et al. Efficacy and safety of conversion from twice-daily to once-daily tacrolimus in a large cohort of stable kidney transplant recipients. Am J Transplant. 2011;11:1965-1971.

43. Slatinska J, Rohal T, Wohlfahrtova M, Viklicky O. Long-term follow-up of stable kidney transplant recipients after conversion from tacrolimus twice daily immediate release to tacrolimus once-daily prolonged release: a large single-center experience. Transplant Proc. 2013;45: 1491-1496.

44. Kurnatowska I, Krawczyk J, Oleksik T, Nowicki M. Tacrolimus dose and blood concentration variability in kidney transplant recipients undergoing conversion from twice daily to once daily modified release tacrolimus. Transplant Proc. 2011;43:2954-2956.

45. Sabbatini M, Garofalo G, Borrelli S, et al. Efficacy of a reduced pill burden on therapeutic adherence to calcineurin inhibitors in renal transplant recipients: an observational study. Patient Prefer Adherence. 2014;8:73-81.

46. Wu SW, Tsai HC, Tsai PY, Hung TW, Chang HR, Lian JD. Conversion to prolonged release tacrolimus formulation in stable kidney transplant recipients. Swiss Med Wkly. 2013;143:w13850.

47. Ma MK, Kwan LP, Mok MM, Yap DY, Tang CS, Chan TM. Significant reduction of Tacrolimus trough level after conversion from twice daily Prograf to once daily Advagraf in Chinese renal transplant recipients with or without concomitant diltiazem treatment. Ren Fail. 2013;35:942-945.
48. Sessa A, Esposito A, Iavicoli G, et al. Cardiovascular risk factors in renal transplant patients after switch from standard tacrolimus to prolongedrelease tacrolimus. Transplant Proc. 2012;44:1901-1906.

49. van Hooff J, Van der Walt I, Kallmeyer J, et al. Pharmacokinetics in stable kidney transplant recipients after conversion from twice-daily to once-daily tacrolimus formulations. Ther Drug Monit. 2012;34: 46-52.

50. Nakamura Y, Hama K, Katayama H, et al. Safety and efficacy of conversion from twice-daily tacrolimus (prograf) to once-daily prolonged-release tacrolimus (graceptor) in stable kidney transplant recipients. Transplant Proc. 2012;44:124-127.

51. Lauzurica R, Morales JM, van Hooff J; Study Investigators. Renal function and safety in stable kidney transplant recipients converted from immediate-release to prolonged-release tacrolimus. Transpl Int. 2012;25:48-55.

52. Uchida J, Kuwabara N, Machida Y, et al. Conversion of stable kidney transplant recipients from a twice-daily prograf to a once-daily tacrolimus formulation: a short-term study on its effects on glucose metabolism. Transplant Proc. 2012;44:128-133.

53. Midtvedt K, Jenssen T, Hartmann A, et al. No change in insulin sensitivity in renal transplant recipients converted from standard to oncedaily prolonged release tacrolimus. Nephrol Dial Transplant. 2011;26: 3767-3772.

54. Kolonko A, Chudek J, Wiecek A. Improved kidney graft function after conversion from twice daily tacrolimus to a once daily prolongedrelease formulation. Transplant Proc. 2011;43:2950-2953.

55. Glowacki F, Lionet A, Hammelin JP, et al. Influence of cytochrome P450 3A5 (CYP3A5) genetic polymorphism on the pharmacokinetics of the prolonged-release, once-daily formulation of tacrolimus in stable renal transplant recipients. Clin Pharmacokinet. 2011;50:451-459.

56. Iaria G, Sforza D, Angelico R, et al. Switch from twice-daily tacrolimus (Prograf) to once-daily prolonged-release tacrolimus (Advagraf) in kidney transplantation. Transplant Proc. 2011;43:1028-1029.

57. de Jonge H, Kuypers DR, Verbeke K, Vanrenterghem Y. Reduced $\mathrm{C} 0$ concentrations and increased dose requirements in renal allograft recipients converted to the novel once-daily tacrolimus formulation. Transplantation. 2010;90:523-529.

58. Glick L, Shamy F, Nash M, et al. A prospective cohort conversion study of twice-daily to once-daily extended-release tacrolimus: role of ethnicity. Transplant Res. 2014;3:7.

59. Diez Ojea B, Alonso Alvarez M,Aguado Fernández S, Baños Gallardo M, García Melendreras S, Gómez Huertas E. Three-month experience with tacrolimus once-daily regimen in stable renal allografts. Transplant Proc. 2009;41:2323-2325.

60. Mecule A, Poli L, Nofroni I, et al. Once daily tacrolimus formulation: monitoring of plasma levels, graft function, and cardiovascular risk factors. Transplant Proc. 2010;42:1317-1319.

61. Tinti F, Mecule A, Poli L, et al. Improvement of graft function after conversion to once daily tacrolimus of stable kidney transplant patients. Transplant Proc. 2010;42:4047-4048.

62. Hougardy JM, Broeders N, Kianda M, et al. Conversion from Prograf to Advagraf among kidney transplant recipients results in sustained decrease in tacrolimus exposure. Transplantation. 2011;91:566-569.

63. Wehland M, Bauer S, Brakemeier S, et al. Differential impact of the CYP3A5*1 and CYP3A5*3 alleles on pre-dose concentrations of two tacrolimus formulations. Pharmacogenet Genomics. 2011;21: 179-184.

64. Calia R, Lai C, Aceto P, et al. Effects of switching from twice-daily to once-daily tacrolimus formulation on quality of life, anxiety, and transplant benefit perception after kidney transplantation. Transplant Proc. 2011;43:1020-1023.

65. Mecule A, Tinti F, Poli L, et al. Tacrolimus trough levels and level-todose ratio in stable renal transplant patients converted to a once-daily regimen. Transplant Proc. 2011;43:1024-1027.

66. $\mathrm{Wu} \mathrm{MJ}$, Cheng $\mathrm{CY}$, Chen $\mathrm{CH}$, et al. Lower variability of tacrolimus trough concentration after conversion from prograf to advagraf in stable kidney transplant recipients. Transplantation. 2011;92:648-652. 
67. Uchida J, Iwai T, Kabei K, et al. Effects of conversion from a twice-daily tacrolimus to a once-daily tacrolimus on glucose metabolism in stable kidney transplant recipients. Transplant Proc. 2014;46:532-536.

68. Alloway R, Steinberg S, Khalil K, et al. Two years postconversion from a prograf-based regimen to a once-daily tacrolimus extended-release formulation in stable kidney transplant recipients. Transplantation. 2007;83:1648-1651.

69. Bäckman L, Persson CA. An observational study evaluating tacrolimus dose, exposure, and medication adherence after conversion from twice- to once-daily tacrolimus in liver and kidney transplant recipients. Ann Transplant. 2014;19:138-144.

70. Tsuchiya T, Ishida K, Ito S, Deguchi T. Effect of conversion from twice-daily to once-daily tacrolimus on glucose intolerance in stable kidney transplant recipients. Transplant Proc. 2012;44:118-120.

71. Hatakeyama S, Fujita T, Yoneyama T, et al. A switch from conventional twice-daily tacrolimus to once-daily extended-release tacrolimus in stable kidney transplant recipients. Transplant Proc. 2012;44: 121-123.

72. Rostaing L, Sánchez-Fructuoso A, Franco A, Glyda M, Kuypers DR, Jaray J. Conversion to tacrolimus once-daily from ciclosporin in stable kidney transplant recipients: a multicenter study. Transpl Int. 2012;25:391-400

73. Veroux M, Grosso G, Ekser B, Corona D, Giaquinta A, Veroux P. Impact of conversion to a once daily tacrolimus-based regimen in kidney transplant recipients with gastrointestinal complications. Transplantation. 2012;93:895-899.

74. van Boekel GA, Kerkhofs CH, Hilbrands LB. Treatment satisfaction in renal transplant patients taking tacrolimus once daily. Clin Ther. 2013;35:1821-1829. e1.

75. Wu MJ, Chang CH, Cheng CY, et al. Reduced variability of tacrolimus trough level in once-daily tacrolimus-based Taiwanese kidney transplant recipients with high-expressive genotype of cytochrome P450 3A5. Transplant Proc. 2014;46:403-405.

76. Bunnapradist S, Ciechanowski K, West-Thielke P, et al. Conversion from twice-daily tacrolimus to once-daily extended release tacrolimus (LCPT): the phase III randomized MELT trial. Am J Transplant. 2013;13:760-769.

77. Alloway R, Steinberg S, Khalil K, et al. Conversion of stable kidney transplant recipients from a twice daily Prograf-based regimen to a once daily modified release tacrolimus-based regimen. Transplant Proc. 2005;37:867-870

78. Muduma G, Odeyemi I, Pollock RF. A UK analysis of the cost of switching renal transplant patients from an immediate-release to a prolonged-release formulation of tacrolimus based on differences in trough concentration variability. J Med Econ. 2014;17: $520-526$.

79. Kuypers DR, Peeters PC, Sennesael JJ, et al. Improved adherence to tacrolimus once-daily formulation in renal recipients: a randomized controlled trial using electronic monitoring. Transplantation. 2013;95:333-340.

80. Weiler N, Thrun I, Eberlin M, et al. Tacrolimus effects and side effects after liver transplantation: is there a difference between immediate and extended release? Transplant Proc. 2013;45:2321-2325.

81. Merli M, Di Menna S, Giusto M, et al. Conversion from twice-daily to once-daily tacrolimus administration in liver transplant patient. Transplant Proc. 2010;42:1322-1324.

Transplant Research and Risk Management

\section{Publish your work in this journal}

Transplant Research and Risk Management is an international, peerreviewed open access journal focusing on all aspects of transplantation and risk management to achieve optimal outcomes in the recipient improving survival and quality of life. The journal welcomes submitted papers covering original research, basic science, clinical studies,
82. Beckebaum S, Iacob S, Sweid D, et al. Efficacy, safety, and immunosuppressant adherence in stable liver transplant patients converted from a twice-daily tacrolimus-based regimen to once-daily tacrolimus extended-release formulation. Transpl Int. 2011;24:666-675.

83. Zhang YF, Chen XY, Dai XJ, Leng XS, Zhong DF. Pharmacokinetics of tacrolimus converted from twice-daily formulation to once-daily formulation in Chinese stable liver transplant recipients. Acta Pharmacol Sin. 2011;32:1419-1423.

84. Dopazo C, Rodriguez R, Llado L, et al. Successful conversion from twice-daily to once-daily tacrolimus in liver transplantation: observational multicenter study. Clin Transplant. 2012;26:E32-E37.

85. Dumortier J, Guillaud O, Boillot O. Conversion from twice daily tacrolimus to once daily tacrolimus in long-term stable liver transplant recipients: a single-center experience with 394 patients. Liver Transpl. 2013;19:529-533.

86. Giannelli V, Rossi M, Giusto M, et al. Conversion from twice-daily to once-daily Tacrolimus administration in liver transplant patient: results of long term follow-up. Eur Rev Med Pharmacol Sci. 2013;17:2718-2720.

87. Comuzzi C, Lorenzin D, Rossetto A, et al. Safety of conversion from twice-daily tacrolimus (Prograf) to once-daily prolonged-release tacrolimus (Advagraf) in stable liver transplant recipients. Transplant Proc. 2010;42:1320-1321.

88. Florman S, Alloway R, Kalayoglu M, et al. Conversion of stable liver transplant recipients from a twice-daily Prograf-based regimen to a once-daily modified release tacrolimus-based regimen. Transplant Proc. 2005;37:1211-1213.

89. Eberlin M, Otto G, Kramer I. Increased medication compliance of liver transplant patients switched from a twice-daily to a once-daily tacrolimus-based immunosuppressive regimen. Transplant Proc. 2013;45:2314-2320.

90. Valente G, Rinaldi L, Sgambato M, Piai G. Conversion from twice-daily to once-daily tacrolimus in stable liver transplant patients: effectiveness in a real-world setting. Transplant Proc. 2013;45:1273-1275.

91. Florman S, Alloway R, Kalayoglu M, et al. Once-daily tacrolimus extended release formulation: experience at 2 years postconversion from a Prograf-based regimen in stable liver transplant recipients. Transplantation. 2007;83:1639-1642.

92. Sańko-Resmer J, Boillot O, Wolf P, Thorburn D. Renal function, efficacy and safety postconversion from twice- to once-daily tacrolimus in stable liver recipients: an open-label multicenter study. Transpl Int. 2012;25:283-293

93. Alloway RR, Eckhoff DE, Washburn WK, Teperman LW. Conversion from twice daily tacrolimus capsules to once daily extended-release tacrolimus (LCP-Tacro): phase 2 trial of stable liver transplant recipients. Liver Transpl. 2014;20:564-575.

94. Marin-Gomez LM, Gomez-Bravo MA, Alamo-Martinez JA, et al. Evaluation of clinical safety of conversion to Advagraf therapy in liver transplant recipients: observational study. Transplant Proc. 2009;41: 2184-2186.

95. Quteineh L, Verstuyft C, Furlan V, et al. Influence of CYP3A5 genetic polymorphism on tacrolimus daily dose requirements and acute rejection in renal graft recipients. Basic Clin Pharmacol Toxicol. 2008;103: 546-552.

reviews \& evaluations, guidelines, expert opinion and commentary, case reports and extended reports. The manuscript management system is completely online and includes a very quick and fair peer-review system, which is all easy to use. Visit http://www.dovepress.com/ testimonials.php to read real quotes from published authors. 